\title{
Inhibitory Effect of Coptidis Rhizoma and Scutellariae Radix on Azoxymethane-Induced Aberrant Crypt Foci Formation in Rat Colon
}

\author{
Masato Fukutake, ${ }^{*, a}$ Shigeru Yokota, ${ }^{b}$ Hideki Kamamura, ${ }^{a}$ Akira Iizuka, ${ }^{a}$ Sakae Amagaya, ${ }^{a}$ \\ Kazunori FUKUDA, ${ }^{a}$ and Yasuhiro KOMATSU ${ }^{a}$ \\ Central Research Laboratories, Tsumura \& Co., 3586 Yoshiwara, Ami-machi, Inashiki-gun, Ibaraki 300-1192, Japan and \\ Laboratory of Molecular Biology, School of Hygenic Sciences, Kitasato University, ${ }^{b}$ 1-15-1 Kitasato, Sagamihara \\ 228-8555, Kanagawa, Japan. Received January 14, 1998; accepted May 11, 1998
}

This study was conducted to obtain effective cancer chemopreventive agents with low toxicity from medicinal herbs. The effect of aqueous extracts from 9 medicinal herbs with antiinflammatory effect were examined on the formation of azoxymethane (AOM)-induced aberrant crypt foci (ACF), putative preneoplastic lesions of the colon. Male F344 rats were treated with $15 \mathrm{mg} / \mathrm{kg}$ body weight of AOM once a week for two weeks. Herbal extract consisting of $2 \%$ of the diet was administered from $1 \mathrm{~d}$ prior to the first carcinogen treatment. The number of AOM-induced ACF per colon was counted at 4 week. Extracts of Coptidis Rhizoma and Scutellariae Radix significantly inhibited AOM-induced ACF formation. The number of ACF was decreased to $54 \%$ and $78 \%$ of that of the control by $2 \%$ Coptidis Rhizoma and Scutellariae Radix extract in the diet, respectively. Berberine and Baicalin, major ingredients of Coptidis Rhizoma and Scutellariae Radix, inhibited ACF formation at a dose equivalent to the amount in each herbal extract.

Therefore, to investigate the mechanisms of action of berberine and baicalein which is the active substances of orally administered baicalin, their effects on cyclooxygenase 1 and 2 activities were studied. Berberine was found to inhibit cyclooxygenase 2 activity without inhibition of cyclooxygenase 1 activity, and baicalein inhibited cyclooxygenase 1 activity.

Thus, Coptidis Rhizoma and Scutellariae Radix suppressed experimental colon carcinogenesis, and their chemopreventive effects were explained from the inhibition of berberine on cyclooxygenase 2 activity and baicalein on cyclooxygenase 1 activity.

Key words aberrant crypt foci (ACF); inhibitor; Coptidis Rhizoma; Scutellariae Radix; berberine; baicalin

Colon cancer is a major cause of death in many countries including Japan and the search for chemopreventive agents for treating colon cancer is a very important subject. A diet rich in vegetables, fruits, and grains has been shown to lessen the risk of various cancers including colon cancer. ${ }^{1-3)}$ Natural compounds possessing anticarcinogenic properties from foods should prove to be quite useful for primary colon cancer prevention. ${ }^{2-7)} \omega 3$ poly unsaturated fatty acids, ${ }^{8-10)}$ calcium salts ${ }^{11)}$ and inorganic and organic selenium compounds ${ }^{12)}$ express chemopreventive effect in colon carcinogenesis. Chemopreventive agents with more potent efficacy are required for patients with high risk factors for colon cancer such as familial polyposis or ulcerative colitis. Nonsteroidal antiinflammatory drugs (NSAIDs) including piroxicam, sulindac, indomethacin and aspirin have potent chemopreventive effect which counters colon cancers. ${ }^{7,13-20)}$ But most of these drugs have adverse effects, which may be lifethreatening, especially at higher doses. ${ }^{21)}$

In chemoprevention, effective compounds with low toxicity are desirable. ${ }^{21)}$ From this standpoint, the investigation of medicinal herbs would be of interest. Herbal extract constituents express cytostatic, antiinflammatory and antioxidative effects, suggesting their possible use as chemopreventive drugs. ${ }^{22,23)}$ The chemopreventive efficacy of medicinal herbs in an established colon carcinogenesis model should thus be assessed.

Azoxymethane (AOM)-induced aberrant crypt foci (ACF) in rat colon are putative preneoplastic lesions and many substances have been examined to reduce AOM-induced ACF. But effective compounds without adverse effect in clinical

* To whom correspondence should be addressed. treatment have not been found.

In this research, we studied the medicinal herbs Coptidis Rhizoma and Scutellariae radix on the formation of colon carcinogenesis with low adverse effect.

\section{MATERIALS AND METHODS}

Materials Medicinal herb extracts were prepared by boiling in water followed by spray-drying to obtain extract powder. Each powder was weighed and mixed in the diet at specified content. The powders were prepared at Tsumura \& Co. (Tokyo, Japan). AOM and piroxicam were obtained from Sigma Chemical Co. (St. Louis, MO, U.S.A.). Berberine and baicalin were from Wako Pure Chemical Industries Ltd. (Osaka, Japan).

Animals and Experimental Protocols Male F344 rats (6 weeks old) were purchased from Charles River Japan, Inc. (Kanagawa, Japan). The animals were housed three per plastic cage in an air-conditioned room with a 12-h light-dark cycle. All rats were provided the AIN-76A powder diet (Diets Inc., PA, U.S.A.) and water ad libitum and weighed weekly. Nine rats were used in each group. The rats were given subcutaneous injections of AOM $(15 \mathrm{mg} / \mathrm{kg}$ body weight) in sterile saline once a week for 2 weeks. Each herbal extract or its component was mixed in the diet and fed throughout the experiment from $1 \mathrm{~d}$ before the first injection of AOM. In the control group, basal diet was fed through the term of experiment. All animals were sacrificed and the frequency of colonic ACF was determined 4 weeks after the first carcinogen treatment. The colons of the animals were re- 
moved and filled with $10 \%$ formalin. After 5-10 min, the colon was slit open longitudinally from the anus to cecum, spread flat between sheets of filter paper and fixed in buffered $10 \%$ formalin. The specimens were then stained with $0.2 \%$ methylene blue in saline to observe aberrant crypts (ACs) as previously reported. ${ }^{24,25)}$ The number of ACF per colon and number of ACs in each focus were counted by microscopy at a magnification of $\times 40$. Statistical analysis was conducted in all cases using the Mann-Whitney test.

Cyclooxygenase 1 (COX 1) and Cyclooxygenase 2 (COX 2) Assay COX 1 and COX 2 were suspended in $0.5 \mathrm{ml}$ of $100 \mathrm{~mm}$ Tris- $\mathrm{HCl}$ buffer ( $\mathrm{pH} 8.0$ ) containing hematin $(1 \mu \mathrm{M})$ and phenol $(2 \mathrm{~mm})$, as co-factors. The reaction mixture was preincubated with drug for $2 \mathrm{~min}$ at $37^{\circ} \mathrm{C}$, then $100 \mu \mathrm{M}$ of arachidonate was added and incubated for $2 \mathrm{~min}$ at $37^{\circ} \mathrm{C}$. To terminate the reaction and extract prostaglandin $\mathrm{E}_{2}\left(\mathrm{PGE}_{2}\right)$, $2 \mathrm{ml}$ of $n$-hexane/ethyl acetate $(2: 1, \mathrm{v} / \mathrm{v})$ was added to the reaction mixture and the preparation centrifuged at $3000 \mathrm{rpm}$ for $10 \mathrm{~min}$. The amount of $\mathrm{PGE}_{2}$ was measured by enzyme immunoassay (EIA) using PGE $_{2}$ EIA kits.

\section{RESULTS}

The Effects of Medicinal Herb Extracts on AOM-Induced ACF Formation The effects of medicinal herb extracts, mixed in the diet at a concentration of $2 \%$, on AOMinduced ACF formation were examined and the results are shown in Table 1. ACF were found in the colons of all animals treated with AOM. ACF were located mainly in the middle and distal colon, a few in the rectum and very few in the proximal colon. The extracts of Coptidis Rhizoma and Scutellariae Radix decreased the number of ACF significantly. The average number of ACF in rats treated with the extracts of Coptidis Rhizoma and Scutellariae Radix was 54 and $78 \%$ that of the control group, respectively. Mean ACF size, measured as the number of ACs per focus, was also significantly smaller in rats given the extracts of Coptidis Rhizoma than that of the control group.
Dose-Dependent Inhibition of Coptidis Rhizoma Extract or Scutellariae Radix Extract on AOM-Induced ACF Formation Figure 1 shows the dose-dependent effects of the extracts of Coptidis Rhizoma and Scutellariae Radix on the number of AOM-induced ACF and on body weight.

The extracts of Coptidis Rhizoma decreased the number of ACF dose-dependently. Treatment with $2 \%$ Coptidis Rhizoma extract reduced the number of ACF to $54 \%$ that of the control. Body weight loss was essentially in proportion to the degree of inhibition of ACF formation. Diet intake was also decreased by the administration of Coptidis Rhizoma extract. The decreasing ratio of body weight and diet intake was almost the same. They were $39.1 \%$ and $40.8 \%$ respectively. Scutellariae Radix decreased the number of $\mathrm{ACF}$ to about $80 \%$ of the control at 1 and $2 \%$ in the diet. No significant weight loss was observed in rats treated with Scutellariae Radix extract up to $2 \%$ in the diet.

Inhibitory Effects of Berberine and Baicalin on AOMInduced ACF Formation Berberine and baicalin, the major ingredients of Coptidis Rhizoma and Scutellariae Radix, decreased the number of ACF to 70.9 and $88.4 \%$ that of the control at a dose equivalent to the $2 \%$ herbal extract content (i.e. $0.08 \%$ berberine and $0.2 \%$ baicalin) (Table 2 ). Furthermore, Coptidis Rhizoma extract decreased ACF size, while berberine had no effect. As for the body weight, berberine did not show the body weight loss which was seen in the Coptidis Rhizoma group.

Influence of Berberine, Baicalin and Baicalein on the Enzyme Activity of COX 1 and COX 2 Berberine at a concentration of $100 \mu \mathrm{g} / \mathrm{ml}$ inhibited COX 2 activity by the inhibitory ratio of $31.6 \%$, although COX 1 activity was not affected. In contrast, baicalein, which is an aglycone of baicalin, mainly inhibited COX 1 activity, and both COX 1 and COX 2 activities were unaffected by baicalin even at the highest concentration $(100 \mu \mathrm{g} / \mathrm{ml})$ (Figure 2).

Table 1. Effects of Medicinal Herb Extracts on AOM-Induced ACF in Rat Colon

\begin{tabular}{|c|c|c|c|c|}
\hline Treatment & $\begin{array}{l}\text { No. of rats } \\
\text { with } \mathrm{AC}\end{array}$ & $\begin{array}{c}\text { No. of } \\
\text { ACF/colon }{ }^{a)}\end{array}$ & $\begin{array}{c}\text { No. of } \\
\text { ACs } / \text { colon }^{(a)}\end{array}$ & $\begin{array}{l}\text { Mean No. of } \\
\text { ACs/focus }\end{array}$ \\
\hline Basal diet & $9 / 9$ & $\begin{array}{c}137.1 \pm 46.3 \\
(100 \%)\end{array}$ & $\begin{array}{c}234.2 \pm 86.6 \\
(100 \%)\end{array}$ & $\begin{array}{c}1.69 \pm 0.12 \\
(100 \%)\end{array}$ \\
\hline Coptidis Rhizoma & $9 / 9$ & $\begin{array}{l}73.3 \pm 33.5^{b)} \\
(54 \%)\end{array}$ & $\begin{array}{c}112.7 \pm 59.1^{b)} \\
(48 \%)\end{array}$ & $\begin{array}{c}1.48 \pm 0.14^{b)} \\
(88 \%)\end{array}$ \\
\hline Scutellariae Radix & $9 / 9$ & $\begin{array}{c}106.5 \pm 24.0^{b)} \\
(78 \%)\end{array}$ & $\begin{array}{c}193.1 \pm 40.3 \\
(83 \%)\end{array}$ & $\begin{array}{c}1.80 \pm 0.09 \\
(107 \%)\end{array}$ \\
\hline Phellodendri Cortex & $9 / 9$ & $\begin{array}{c}115.6 \pm 29.7 \\
(84 \%)\end{array}$ & $\begin{array}{c}200.1 \pm 148.2 \\
(85 \%)\end{array}$ & $\begin{array}{c}1.71 \pm 0.06 \\
(101 \%)\end{array}$ \\
\hline Platycodi Radix & $9 / 9$ & $\begin{array}{c}126.7 \pm 21.6 \\
(92 \%)\end{array}$ & $\begin{array}{c}224.9 \pm 117.3 \\
(96 \%)\end{array}$ & $\begin{array}{c}1.78 \pm 0.02 \\
(105 \%)\end{array}$ \\
\hline Zingiberis Rhizoma & $9 / 9$ & $\begin{array}{c}127.1 \pm 16.7 \\
(93 \%)\end{array}$ & $\begin{array}{c}216.1 \pm 81.4 \\
(92 \%)\end{array}$ & $\begin{array}{c}1.71 \pm 0.02 \\
(101 \%)\end{array}$ \\
\hline Bupleuri Radix & $9 / 9$ & $\begin{array}{c}130.8 \pm 11.8 \\
(95 \%)\end{array}$ & $\begin{array}{c}223.5 \pm 64.4 \\
(95 \%)\end{array}$ & $\begin{array}{c}1.67 \pm 0.04 \\
(99 \%)\end{array}$ \\
\hline Persicae Semen & $9 / 9$ & $\begin{array}{c}135.1 \pm 21.9 \\
(99 \%)\end{array}$ & $\begin{array}{c}234.7 \pm 113.6 \\
(100 \%)\end{array}$ & $\begin{array}{c}1.75 \pm 0.05 \\
(104 \%)\end{array}$ \\
\hline Schizonepetae Spica & $9 / 9$ & $\begin{array}{c}139.3 \pm 45.3 \\
(102 \%)\end{array}$ & $\begin{array}{c}248.7 \pm 87.0 \\
(106 \%)\end{array}$ & $\begin{array}{c}1.74 \pm 0.12 \\
(103 \%)\end{array}$ \\
\hline Cimicifugae Rhizoma & $9 / 9$ & $\begin{array}{c}146.7 \pm 66.6 \\
(107 \%)\end{array}$ & $\begin{array}{c}252.6 \pm 118.0 \\
(108 \%)\end{array}$ & $\begin{array}{c}1.72 \pm 0.13 \\
(102 \%)\end{array}$ \\
\hline
\end{tabular}

a) Data are means \pm S.D. b) Significantly different from control value at $p<0.005$. 

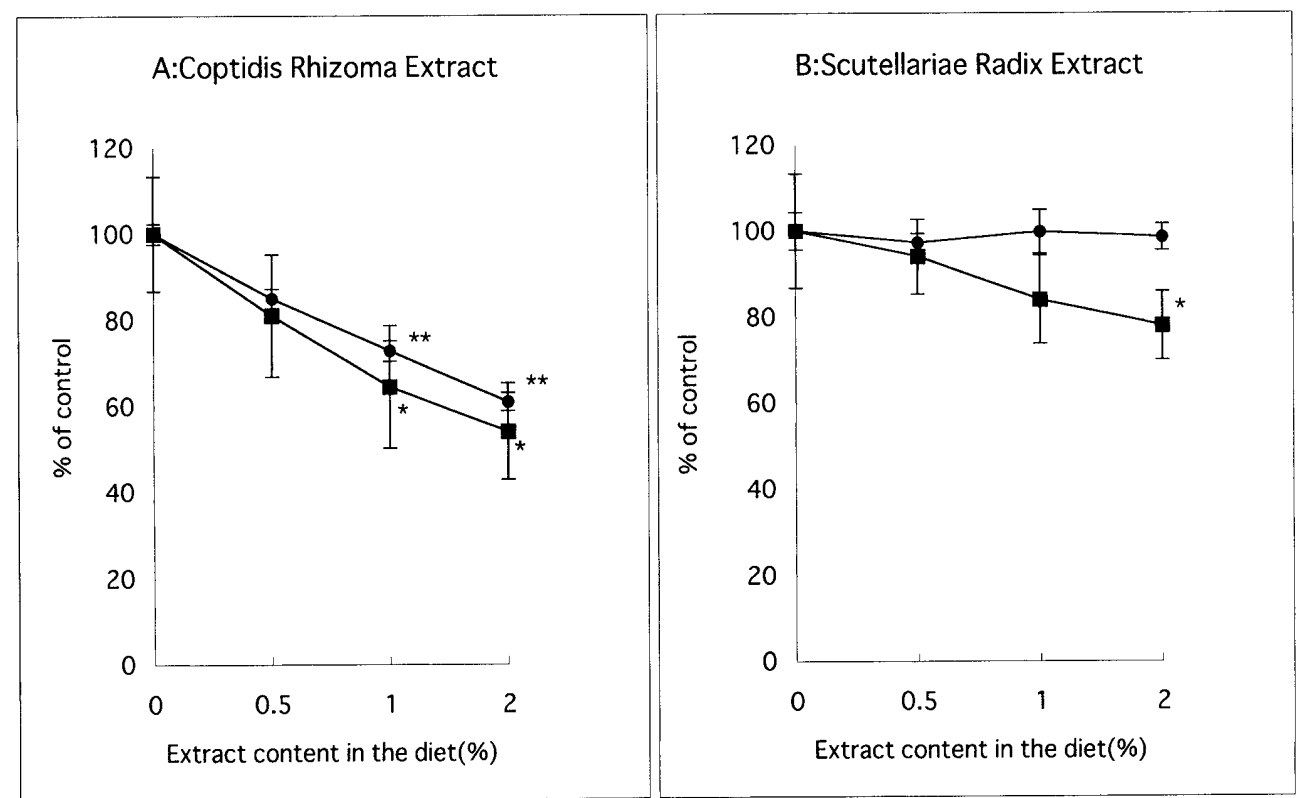

Fig. 1. Changes in the Number of ACF and Body Weight

by Administration of Various Doses of Coptidis Rhizoma Extract (A) and Scutellariae Radix Extract (B)

Body weight and number of ACF are presented as a percentage of the control values, which are determined at each dose. $*: p<0.05, * *: p<0.005$.

\section{$\cos 2$}

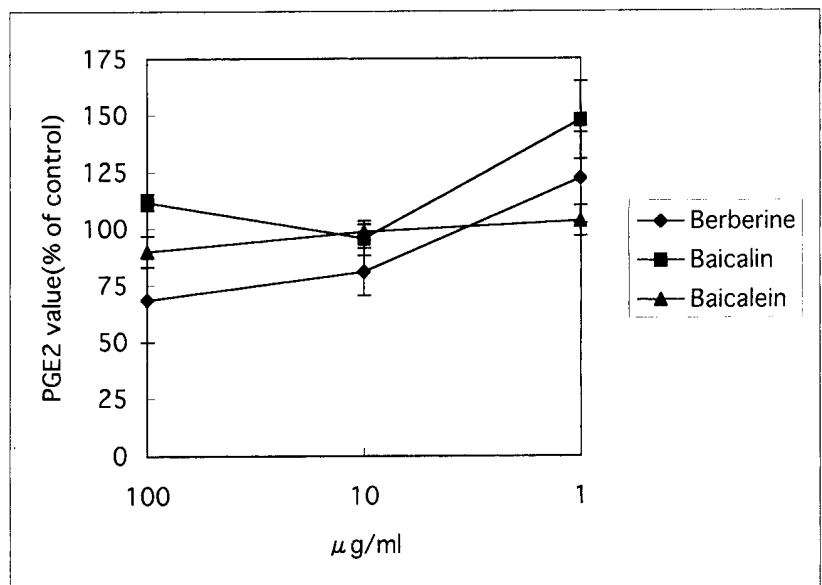

\section{$\operatorname{cox} 1$}

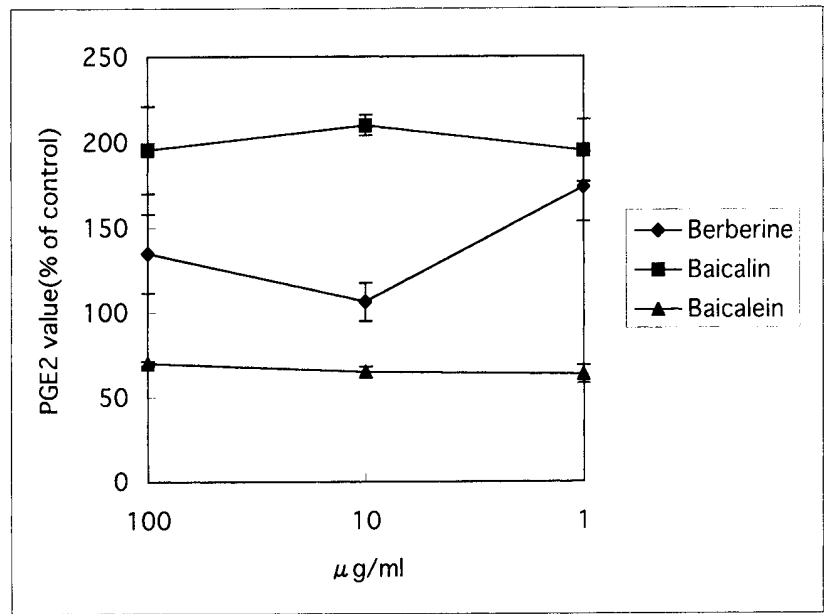

Fig. 2. Influence of Berberine $(\bullet)$, Baicalin $(\boldsymbol{\square})$ and Baicalein $(\boldsymbol{\Delta})$ on the Enzyme Activity of COX 1 and $\mathrm{COX} 2$

The enzyme activity was determined by inhibitory ratio of $\mathrm{PGE}_{2}$ production from arachidonic acid.
Table 2. Effects of Baicalin and Berberine on AOM-Induced ACF in Rat Colon

\begin{tabular}{lcc}
\hline \hline $\begin{array}{c}\text { \% of test substances } \\
\text { in diet }\end{array}$ & $\begin{array}{c}\text { No. of } \\
\text { ACF/colon }^{(a)}\end{array}$ & $\begin{array}{c}\text { Mean No. of } \\
\text { ACs/focus }^{())}\end{array}$ \\
\hline Control & $128.2 \pm 40.7$ & $1.77 \pm 0.11$ \\
$2 \%$ Coptidis Rhizoma & $(100 \%)$ & $(100 \%)$ \\
& $68.5 \pm 33.5^{b)}$ & $1.55 \pm 0.14^{(3)}$ \\
$0.08 \%$ berberine & $(53.5 \%)$ & $(87.8 \%)$ \\
& $90.9 \pm 37.8$ & $1.85 \pm 0.17$ \\
$2 \%$ Scutellariae Radix & $(70.9 \%)$ & $(104.3 \%)$ \\
$0.2 \%$ baicalin & $106.0 \pm 31.6$ & $1.78 \pm 0.22$ \\
& $(82.7 \%)$ & $(100.6 \%)$ \\
& $113.3 \pm 35.6$ & $1.78 \pm 0.08$ \\
$(88.4 \%)$ & $(100.6 \%)$ \\
\hline
\end{tabular}

a) Data are means \pm S.D. b) Significantly different from control value at $p<0.05$.

\section{DISCUSSION}

Some dietary constituents and medicinal herbs possess strong antiinflammatory and free-radical scavenging activity. ${ }^{4-7,26,27)}$ Many experimental and epidemiological studies show that antioxidants and antiinflammatory drugs suppress mutagenesis and carcinogenesis. ${ }^{2,57)}$ Some medicinal herbs contain various substances that strongly exert antiinflammatory and/or antioxidative effects. Naturally occurring polyphenols such as flavonoids and catechins have received considerable attention as potent chemopreventive agents. Plant polyphenols have several biological activities by which they may exert their protective effects as anticarcinogens. ${ }^{4,6)}$ They inhibit lipoxygenase and cyclooxygenase activity, nitric oxide production, capacity to scavenge oxyradicals and nitric oxide radicals, cytostatic or cytocidal effects, and apoptosis inducing activity. ${ }^{15,16,23,28,29)}$

Scutellariae Radix is rich in flavonoids such as baicalin. In this study, Scutellariae Radix extract was found to express a chemopreventive effect toward colon carcinogenesis, and 
baicalin showed anticarcinogenic properties. Coptidis Rhizoma contains various alkaloids that inhibit various enzymes. Berberine is a benzodioxolo-benzoquinolizine alkaloid present in numerous plants of the genera Berberis and Coptis which have long been used in European and Far Eastern countries for treating gastroenteritis and diarrhea. It has a wide range of pharmacological and biological activity, including antisecretory, ${ }^{30-34)}$ antiinflammatory, ${ }^{35)}$ antimicrobial $^{36-40)}$ and anticancer properties. ${ }^{36,41)}$ Berberine is cytotoxic toward several tumor cells ${ }^{42)}$ and induces apoptosis in HL-60 cells. ${ }^{43)}$ The strong pharmacological and cytotoxical effects of the alkaloid may explain the action of the Coptidis Rhizoma extract. In the present study we have found that berberine decreased the number of $\mathrm{ACF}$ at a dose equivalent to the $2 \%$ herbal extract content. Phellodendri Cortex also contains berberine. The decreasing effect of Phellodendri Cortex on ACF formation was thought to correlate to this activity of berberine. But it was not as effective as Coptidis Rhizoma because the concentration of berberine is lower than in Coptidis Rhizoma. Recently, we reported that nimesulide, a selective COX 2 inhibitor, inhibited ACF formation and development of intestinal polyps in Min mice. ${ }^{44)}$ Therefore, we studied the COX 1 and COX 2 activity of berberine, baicalin and baicalein in vitro to know the mechanism of their inhibition of ACF formation. Berberine showed COX 2 inhibition without COX 1 inhibition. Baicalin was inactive toward both $\operatorname{COX} 1$ and $\operatorname{COX} 2$. Baicalein, an active aglycone of baicalin, inhibited COX 1 only. We think the COX 1 and COX 2 inhibitory activities of these ingredients are the mechanisms of the ACF inhibition of Coptidis Rhizoma and Scutellariae Radix.

Coptidis Rhizoma and Scutellariae Radix are often used for treating inflammatory conditions and digestive organ disorders in some traditional herbal medicines. The present results may thus provide the possibility of Coptidis Rhizoma and Scutellariae Radix for chemoprevention of colon cancer. Berberine and baicalin may contribute to the expression of the inhibitory effects of Coptidis Rhizoma and Scutellariae Radix on ACF formation.

\section{REFERENCES}

1) Thun M. J., Calle E. E., Namboodiri M. M., Dana Flanders W., Coates R. J., Byers T., Boffetta P., Garfinkel L., Heath C. W., Jr., J. Natl. Cancer Inst., 84, 1491-1500 (1992).

2) Ames B. N., Gold L. S., Willett W. C., Proc. Natl. Acad. Sci. U.S.A., 92, 5258-5265 (1995).

3) Alabaster O., Tang Z. C., Frost A., Shivapurkar N., Carcinogenesis, 16, 127-132 (1995)

4) Wattenberg L. W., Cancer Res., 52, 2085s-2091s (1992).

5) Stavric B., Clin. Biochem., 27, 319-332 (1994)

6) Ip C., Lisk D. J., Scimeca J. A., Cancer Res., 54, 1957s-1959s (1994).

7) Greenwald P., Kelloff G. J., Boone C. W., McDonald S. S., Cancer Epidemiology, Biomarkers \& Prevention, 4, 691-702 (1995).

8) Takahashi M., Minamoto T., Yamashita N., Kato T., Yazawa K., Esumi H., Cancer Lett., 83, 177-184 (1994).
9) Takahashi M., Minamoto T., Yamashita N., Yazawa K., Sugimura T., Esumi H., Cancer Res., 53, 2786-2789 (1993).

10) Reddy B. S., Sugie S., Cancer Res., 48, 6642-6647 (1988).

11) Weisburger J. H., Braley J., Reinhardt J., Aliaga C., Rivenson A., Hard G. C., Zhang X.-M., Takahashi M., Esumi H., Sugimura, T., Environ. Health Perspect., 102 (suppl 6), 53-55 (1994).

12) Reddy B. S., Sugie S., Maruyama H., EL-Bayoumy K., Marra P., Cancer Res., 47, 5901-5904 (1987).

13) Reddy B. S., Nayini J., Tokumo K., Rigotty J., Zang E., Kelloff G., Cancer Res., 50, 2562-2568 (1990).

14) Reddy B. S, Tokumo K., Kulkarni N., Aligia C., Kelloff G., Carcinogenesis, 13, 1019-1023 (1992).

15) Reddy B. S., Maruyama H., Kelloff G., Cancer Res., 47, 5340-5346 (1987).

16) Labayle D., Fischer D., Vielh P., Drouhin F., Pariente A., Bories C., Duhamel O., Trousset M., Attali P., Gastroenterology, 101, 635-639 (1991).

17) Thun M., Namboordiri M., Heath C., N. Engl. J. Med., 325, 15931596 (1991)

18) Labayle D., Boyer J., Drouhin F., Zarka Y., Fischer F., Lancet, 343, $417-418$ (1994).

19) Rao C. V., Rivenson A., Simi B., Zang E., Kelloff G., Steele V., Reddy B. S., Cancer Res., 55, $1464-1472$ (1995).

20) Narisawa T., Sato M., Tani M., Kudo T., Takahashi T., Goto A., Cancer Res., 41, 1954-1957 (1981).

21) Trujillo M. A., Garewal H. S., Sampliner R. E., Digestive Diseases and Sciences., 39, 2260-2266 (1994)

22) Okita K., Li Q., Murakami T., Takahashi M., Eur. J. Cancer Prevention, 2, 169-176 (1993).

23) Yano H., Mizoguchi A., Fukuda K., Haramaki M., Ogasawara S., Momosaki S., Kojiro M., Cancer Res., 54, 448-454 (1994).

24) Pereira M. A., Barnes L. H., Rassman V. L., Kelloff G. V., Steele V. E., Carcinogenesis, 15, $1049-1054$ (1994).

25) Bird R. P., Cancer Lett., 37, 147-151 (1987).

26) Ozaki Y., Biol. Pharm. Bull., 18, 559-562 (1995).

27) Sharma S., Stutzman J. D., Kelloff G. J., Steele V. E., Cancer Res., 54, $5848-5855$ (1994)

28) Chan K., Trends Pharmacol. Sci., 16, 182-187 (1995).

29) Reddy B. S., Rao C. V., Carcinogenesis, 14, 1493-1497 (1993)

30) Swabb E. A., Tai Y.-H., Jordan L., Am. J. Physiol., 241, G248-G252 (1981)

31) Snack R. B., Froehlich J. L., Infect. Immun., 35, 471-475 (1982).

32) Tai Y.-H., Feser J. F., Marnane W. G., Desjeux J.-F., Am. J. Physiol., 241, G253-G258 (1981).

33) Zhu B., Ahrens F. A., Eur. J. Pharmacol. 96, 11-19 (1983).

34) Zhu B., Ahrens F. A., Am. J. Vet. Res., 43, 1594--1598 (1982).

35) Fujimura H., Sawada T., Goto M., Yakugaku Zasshi, 90, 782-783 (1970).

36) Creasey W. A., Biochem. Pharmacol., 28, 1081-1084 (1979)

37) Amin A. H., Subbaiah T. V., Abbashi K. M., Can. J. Microbiol., 15, 1067-1076 (1969).

38) Bhakuni D. S., Jain S., "The Alkaloids," Vol.28, ed. by Brossi A., Academic Press, Orlando, 1986, pp. 95--181.

39) Hhan F. E., Ciak J., "Antibiotics," Vol. 3, ed. by Corcoran J. W., Hahn F. E., Springer-Verlag, New York, 1975, pp. 577-584.

40) Ghosh A. K., Bhattacharyya F. K., Ghosh D. K., Exp. Parasitol., 60, 404-413 (1985).

41) Suffness M., Cordell G. A., "The Alkaloids," Vol. 25, ed. by Brossi A., Academic Press, Orlando, 1985, pp. 191-193.

42) Chen K.-T., Hao D.-M., Liu Z.-X., Chen Y.-C., You Z.-S., Chin. Med. J., 107, 808-812 (1994)

43) Kuo C. L., Chou C. C., Young B. Y.-M., Cancer Lett., 93, 193-200 (1995).

44) Nakatsugi S., Fukutake M., Takahashi M., Fukuda K., Isoi T., Taniguchi Y., Sugimura T., Wakabayashi K., Jpn. J. Cancer Res., 88, $1117-1120$ (1997). 